\title{
Endothelial Cell Expression of Vasoconstrictors and Growth Factors Is Regulated by Smooth Muscle Cell-derived Carbon Monoxide
}

Toshisuke Morita and Stella Kourembanas

Joint Program in Neonatology, Department of Pediatrics, Harvard Medical School, Boston, Massachusetts 02115

\begin{abstract}
CO is produced in vascular smooth muscle cells (VSMC) by heme oxygenase-1 (HO-1). CO increases cGMP levels in VSMC; however, its possible additional roles in the vasculature have not been examined. We report that a product of HO, released from VSMC and inhibited by hemoglobin, has paracrine effects on endothelial cells: it increases endothelial cGMP content and decreases the expression of the mitogens, endothelin-1 (ET-1) and platelet-derived growth factor-B (PDGF-B). This product has the characteristics of $\mathrm{CO}$, and its production is increased sevenfold under hypoxia. The VSMC-derived CO caused a fourfold rise in endothelial cell cGMP. In addition, it inhibited the hypoxia-induced increases in mRNA levels of the ET-1 and PDGF-B genes. Inhibitors of $\mathrm{HO}$, and hemoglobin, a scavenger of $\mathrm{CO}$, prevented the rise in cGMP and also restored the hypoxic response of these genes. The inhibition of ET-1 and PDGF$\mathrm{B}$ mRNA by $\mathrm{CO}$ resulted in decreased production of these endothelial-derived mitogens, and in turn, inhibition of VSMC proliferation. These findings suggest an important physiologic role for VSMC-derived $\mathrm{CO}$ in modulating cellcell interaction and cell proliferation in the vessel wall during hypoxia. (J. Clin. Invest. 1995. 96:2676-2682.) Key words: hypoxia - vessel tone - gene regulation - heme oxygenase $\cdot$ endothelin
\end{abstract}

\section{Introduction}

Endothelial-derived NO maintains normal vascular tone through the regulation of cGMP levels in vascular smooth muscle cells (VSMC). ${ }^{1}$ Increased cellular cGMP causes relaxation of VSMC and may affect permeability and coagulant function in endothelial cells $(1,2)$. We reported that $\mathrm{CO}$, a molecule similar to

Address correspondence to Stella Kourembanas, Joint Program in Neonatology, Children's Hospital, 300 Longwood Avenue, Enders 9, Boston, MA 02115-5737. Phone: 617-355-6416; FAX: 617-355-7677; E-mail: KOUREMBANAS@A1.TCH.HARVARD.EDU

Received for publication 10 May 1995 and accepted in revised form 18 August 1995.

1. Abbreviations used in this paper: BAEC, bovine aortic endothelial cells; CoPP-9, cobalt protoporphyrin IX; ET-1, endothelin-1; HbCO, carboxyhemoglobin; HO, heme oxygenase; HUVEC, human umbilical vein endothelial cell; L-NNA, $\mathbf{N}^{\omega}$-nitro-L-arginine; NOS, nitric oxide synthase; SnPP-9, tin protoporphyrin IX; VSMC, vascular smooth muscle cells; ZnPP-9, zinc protoporphyrin IX.

J. Clin. Invest.

(C) The American Society for Clinical Investigation, Inc.

0021-9738/95/12/2676/07 \$2.00

Volume 96, December 1995, 2676-2682
NO, is synthesized by rat VSMC and is responsible for increasing cGMP levels in these cells under hypoxic conditions (3). These findings suggest that endogenous CO plays an important role in regulating vascular tone.

Hypoxia has profound effects on vascular tone, endothelial permeability, and coagulant function $(4,5)$. It mediates these effects partly by regulating the transcription and release of vasoactive mediators in vascular cells. For instance, the expression of such vasoactive agents as endothelin-1 (ET-1) and plateletderived growth factor-B (PDGF-B) is dramatically induced in endothelial cells exposed to low oxygen tension $(6,7)$, and similarly, vascular endothelial growth factor is induced in smooth muscle cells $(8,9)$. Hypoxia can affect both endothelial and VSMC gene expression independently, and the factors released in this setting can modulate endothelial-VSMC interactions leading to a number of vascular disorders including vasoconstriction and excessive proliferation of VSMC, edema in the lung, and thrombus formation in the venous circulation.

Hypoxia also increases the transcriptional rate of the heme oxygenase-1 (HO-1) gene in VSMC causing a net increase in enzymatic activity (3). HO-1 catalyzes the breakdown of heme to $\mathrm{CO}$ and biliverdin and hence regulates both heme homeostasis in the body and CO levels in VSMC. We have shown that VSMC-derived CO increases cGMP levels in VSMC under conditions of hypoxia (3). However, additional effects of $\mathrm{CO}$ on vascular cells have not been investigated.

Using a coculture system of endothelial cells and VSMC, we designed this study to examine the autocrine and paracrine effects of VSMC-derived CO on these two vascular cell types under both normoxic and hypoxic conditions.

\section{Methods}

Cell culture. Primary cultures of human umbilical vein endothelial cells (HUVECs) were used for the endothelial cell layer because we have previously characterized the expression of ET-1 and PDGF-B in these cells in response to hypoxia. They were subcultured on gelatin-coated plates in the presence of heparin $(15 \mathrm{U} / \mathrm{ml})$ and endothelial growth supplement (2.5 mg/100 ml media; Sigma Chemical Co., St. Louis, MO) in medium 199 (Gibco Laboratories, Grand Island, NY) with $20 \%$ FBS (Hyclone Laboratories, Logan, UT) at $37^{\circ} \mathrm{C}, 5 \% \mathrm{CO}_{2}$, in a humidified incubator. Cells were passaged by trypsinization with 0.025\% trypsin-EDTA (Gibco Laboratories) every 3-4 d and were used between passages 5 and 10. Rat aortic VSMC were used as they were shown to produce $\mathrm{CO}(3)$. VSMC and primary cultures of bovine aortic endothelial cells (BAECs) were grown in Dulbecco's modified Eagle's medium (DME) (JRH Biosciences, Lenexa, KS) with 10\% FBS (Hyclone Laboratories) and were passaged similarly. The hypoxic gas mixture $\left(95 \% \mathrm{~N}_{2}, 5 \% \mathrm{CO}_{2}\right)$ was preanalyzed and infused into airtight incubators with inflow and outflow valves (Billups-Rothenberg, Del $\mathrm{Mar}, \mathrm{CA}$ ) at a flow rate of $3 \mathrm{liters} / \mathrm{min}$ for $15 \mathrm{~min} / \mathrm{d}$ as previously (7).

Coculture system. HUVECs, BAECs, and VSMC were cultured separately in Transwell plates (Costar Corp., Cambridge, MA), and when starting coculture, media were changed to $1 \%$ FBS/DME. VSMC were plated at the bottom and endothelial cells were grown on the insert 
above. The ratio of endothelial cells to VSMC during coculture was $\sim 1: 3$.

RNA analysis. Total cellular RNA was prepared by guanidinium isothiocyanate extraction from HUVECs, BAECs, or VSMC exposed to normoxia and hypoxia for various periods. Total RNA ( $15 \mu \mathrm{g} / \mathrm{lane})$ was separated by electrophoresis on $1 \%$ agarose gels containing formaldehyde and transferred to nitrocellulose membranes by blotting. The filters were hybridized with cDNA probes specific for the rat HO-1 gene (3), the human ET-1 (hET-1) and bovine ET-1 (bET-1) genes (10), and the human transforming growth factor $\beta\left(\mathrm{TGF}_{\beta}\right)$ gene (11). The probe for the PDGF-B chain gene was the 1,300 -bp DNA fragment of simian sarcoma virus clone C60 encoding the v-sis oncogene (12). The cDNA fragments were labeled with $\left[\alpha-{ }^{32} \mathrm{P}\right] \mathrm{dCTP}$ using a standard random-primed reaction to a specific activity of $1-2 \times 10^{9} \mathrm{cpm} / \mu \mathrm{g}$. The membranes were hybridized for $2 \mathrm{~h}$ at $68^{\circ} \mathrm{C}$ in QuikHyb solution (Stratagene, La Jolla, CA) with $2 \times 10^{6} \mathrm{cpm} / \mathrm{ml}$ of probe, and washed twice in $2 \times$ SSC containing $0.1 \%$ SDS at room temperature for $15 \mathrm{~min}$, followed by $0.1 \times \mathrm{SSC} / 0.1 \%$ SDS at $60^{\circ} \mathrm{C}$ for $30 \mathrm{~min}$, and were then exposed to film (X-Omat AR; Eastman Kodak, Rochester, NY) with intensifying screens at $-80^{\circ} \mathrm{C}$. The membranes were subsequently stripped and rehybridized with a ${ }^{32}$ P-labeled, 800-bp Pstl fragment of the mouse $\beta$-actin gene. For quantitation, we scanned autoradiographs with a laser densitometer (Ultroscan XL; LKB Instruments Inc., Bromma, Sweden) running the Gel Scan XL software package (Pharmacia LKB Biotechnology, Piscataway, NJ).

Measurement of ET-1 peptide levels in conditioned media. HUVECs were exposed to hypoxia alone, or hypoxia plus tin protoporphyrin IX (SnPP-9), hemoglobin ( $\mathrm{Hb})$, or $\mathrm{N}^{\omega}$-nitro-L-arginine (L-NNA) in the presence or absence of VSMC for various periods from 6 to $48 \mathrm{~h}$. Parallel cultures were maintained under normoxic conditions. The media conditioned by HUVECs alone or HUVECs with VSMC were collected, spun to remove cells, and kept frozen at $-20^{\circ} \mathrm{C}$ until assay. ET- 1 peptide was measured using a radioimmunoassay kit (Amersham Corp., Arlington Heights, IL) with a detection limit of $10^{-15}$ grams $/ \mathrm{ml}$. The antiserum used in this assay does not cross-react with big endothelin. ET-1 production is shown as ET-1 concentration per cell number ( $\mathrm{pM} / 10^{5}$ cell).

Measurement of carboxyhemoglobin ( $\mathrm{HbCO}$ ) levels in conditioned media. Relative amounts of $\mathrm{CO}$ released into the media were measured by adding $\mathrm{Hb}$ for the last hour of incubation and quantifying $\mathrm{HbCO}$ levels spectrophotometrically using a CO-oximeter (Corning 270; Ciba Corning Diagnostics, Medfield, MA). HbCO gives maximal absorbance at a wavelength of $569 \mathrm{~nm}$ and is calculated as the percentage of total $\mathrm{Hb}$. The appropriate amount of $\mathrm{Hb}$ was determined from a standard curve using exogenous $\mathrm{CO}$ and varying amounts of $\mathrm{Hb}$ over a range of concentrations where the absorbance was linear.

VSMC replication. Cell replication was assessed by counting cells cultured in the Transwell system. After various incubation periods, cells were washed twice with ice-cold PBS, harvested, and centrifuged. Cell pellets were resuspended with ice-cold PBS and counted with a Coulter counter (Coulter Corp., Hialeah, FL). To determine whether ET-1 or PDGF-B were active in stimulating VSMC replication, polyclonal antibodies to ET-1 (1:4,000 dilution) and PDGF ( $25 \mu \mathrm{g} / \mathrm{ml})$ were added from the beginning of coculture. The concentrations of antibodies were determined empirically.

cGMP accumulation in hypoxia-exposed HUVECs. To determine the relationship between cGMP concentration and the production of $\mathrm{CO}$ by VSMC, HUVECs were exposed to hypoxia for $6,12,24$, and $48 \mathrm{~h}$ and cGMP concentrations were determined at each time point, in the presence of the phosphodiesterase inhibitor, isobutylmethylxanthine (1 $\mathrm{mM}$ ) added to the media $20 \mathrm{~min}$ before obtaining cell extracts. The effect of SnPP-9 on hypoxia-induced cGMP accumulation was evaluated by exposing cells to hypoxia for $12 \mathrm{~h}$ and adding SnPP-9 to give a final concentration of $10 \mu \mathrm{M}$ or $1 \mathrm{mM}$ in the media, $1 \mathrm{~h}$ before the end of the exposure period. To examine if the CO generated from VSMC regulates cGMP levels, we added $\mathrm{Hb}$ to give a final concentration of 1 or $50 \mu \mathrm{M}$ to the cultures $1 \mathrm{~h}$ before the end of the exposure period, and cGMP concentration was determined. To eliminate the role of NO on hypoxia-induced cGMP accumulation, cells were incubated in L-argi- nine-free medium for $24 \mathrm{~h}$ and then exposed to hypoxia for $12 \mathrm{~h}$. The nitric oxide synthase (NOS) inhibitor L-NNA ( $2.5 \mathrm{mM})$ was added to plates $1 \mathrm{~h}$ before the end of the exposure period, and cGMP concentration was determined in the presence of isobutylmethylxanthine.

Measurement of cGMP concentration. cGMP was extracted from the cells by rapid aspiration of medium, ice-cold PBS washes, and the addition of ice-cold ethanol to give a final concentration of $65 \%$. The cells were harvested and centrifuged at $2,000 \mathrm{~g}$ for $5 \mathrm{~min}$ at $4^{\circ} \mathrm{C}$. Supernatant was transferred to fresh tubes, evaporated under $60^{\circ} \mathrm{C}$ vacuum oven until completely dry, and kept at $-80^{\circ} \mathrm{C}$ until assay. The cGMP concentration in cell extracts was determined by radioimmunoassay (Amersham Corp.). cGMP concentration was normalized to protein content as determined by a dye-binding assay (Bio-Rad Laboratories, Richmond, CA) using bovine serum albumin as standard.

Reagents. SnPP-9, zinc protoporphyrin IX (ZnPP-9), and cobalt protoporphyrin IX (CoPP-9) were purchased from Porphyrin Products, Inc. (Logan, UT). A polyclonal antibody to human ET-1, which showed no cross-reactivity with big endothelin, ET-2, or ET-3, was obtained from Peninsula Laboratories (Belmont, CA). Polyclonal antibody to human PDGF was purchased from Upstate Biotechnology Inc. (Lake Placid, NY). All other reagents used were obtained from Sigma Chemical Co. unless otherwise specified. Pure $\mathrm{Hb}$ was prepared by treatment with excess reducing agents as described previously (3).

Data analysis. Significant differences were determined by one-way ANOVA and $P<0.05$ was considered statistically significant.

\section{Results}

Hypoxia increases HO-1 mRNA levels in VSMC and not in endothelial cells. We reported that VSMC cultured under hypoxic conditions express significantly higher levels of HO-1 than normoxic cells. To determine the expression of HO-1 by VSMC grown in the presence of endothelial cells, HUVECs were cocultured with rat aortic VSMC under hypoxia and RNA was isolated from each cell layer after various time periods of coculture. Under these hypoxic conditions, the $\mathrm{Po}_{2}$ measured in the media was $18-20 \mathrm{mmHg}$, as we reported previously (3). Northern blot analysis of VSMC RNA is shown in Fig. $1 A$ and HUVEC RNA in Fig. $1 B$. HO-1 mRNA levels were induced sevenfold in VSMC exposed to hypoxia for $12 \mathrm{~h}$ while in the presence of endothelial cells. In contrast, HO-1 mRNA levels in the cocultured HUVEC were progressively suppressed under the same hypoxic conditions. Levels of $\beta$-actin mRNA are shown below HO-1. The relative mRNA levels of HO-1 indicated are normalized to those of $\beta$-actin for the corresponding time points. The time course of hypoxia-induced HO-1 mRNA in VSMC cocultured with HUVECs was found to be the same as described previously on VSMC cultured alone (3).

Kinetics of $C O$ production by VSMC in coculture. We have shown that increased HO-1 mRNA results in increased HO-1 activity manifested by the increased release of $\mathrm{CO}(3)$. To determine the production of CO by VSMC grown in the presence of endothelial cells and to examine the kinetics of its release, relative $\mathrm{CO}$ levels in conditioned media were determined as formed $\mathrm{HbCO}$ and measured spectrophotometrically. Fig. 2 shows the relative amounts of $\mathrm{HbCO}$ in media conditioned by VSMC in the presence of HUVECs and compared with levels in media of endothelial cells cultured alone. After hypoxic exposure for $12 \mathrm{~h}, \mathrm{HbCO}$ levels in the conditioned media of VSMC cocultured with HUVECs were increased sevenfold above the levels in normoxic conditioned media and declined to twofold by $48 \mathrm{~h}$ hypoxia. In contrast, HUVECs did not produce $\mathrm{CO}$, as shown by the absence of $\mathrm{HbCO}$ in conditioned media of cells cultured alone under either oxygen condi- 


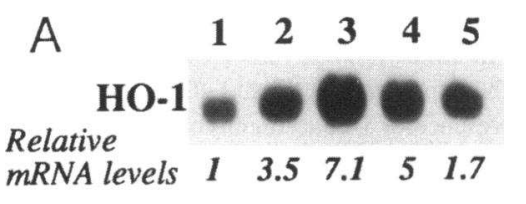

$\beta$-actin

$\begin{array}{llllll}\text { Time (h) } & 0 & 6 & 12 & 24 & 48\end{array}$

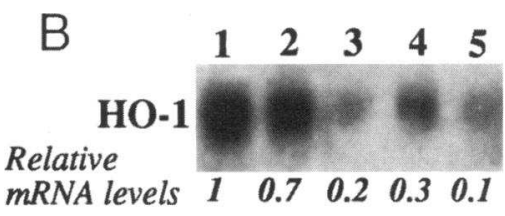

$\beta$-actin

$\begin{array}{llllll}\text { Time (h) } & 0 & 6 & 12 & 24 & 48\end{array}$
Figure 1. HO-1 regulation by hypoxia in VSMC and endothelial cell cocultures. $(A)$ Total RNA was extracted from rat aortic VSMC exposed to hypoxia for $6,12,24$, and $48 \mathrm{~h}$ in the presence of HUVECs cocultured in the Transwell system, and Northern blot analysis was performed. The same blot was hybridized with the $\beta$-actin probe as shown. Relative mRNA levels (normalized to $\beta$ actin mRNA) are indicated in numbers below the HO-1 bands. ( $B$ ) Total RNA was isolated from the HUVECs cultured in Transwell dishes above the VSMC throughout the same experiment described in $A$. Relative HO-1 mRNA levels normalized to $\beta$-actin are indicated. These data are representative of two to four independent experiments where the mean maximal induction of HO-1 was $7.3 \pm 0.36$-fold in VSMC at $12 \mathrm{~h}$ of hypoxia. At $12 \mathrm{~h}, \mathrm{HO}-1$ was reduced to a mean of $0.3 \pm 0.04$ from baseline levels in HUVECs.

tion. The $\mathrm{CO}$ in the conditioned media of cocultured endothelial and VSMC is therefore produced by the VSMC with maximal amounts released after $12 \mathrm{~h}$ of hypoxia.

Hypoxic VSMC increase cGMP levels in HUVECs. VSMCderived CO was shown to regulate cGMP levels in VSMC under normoxic and hypoxic conditions ( 3 ). We thus examined whether VSMC-derived CO can regulate cGMP levels in the adjacent endothelial cells. As shown in Fig. $3 A$, cGMP levels in HUVECs alone were not changed under either normoxic or hypoxic conditions during the indicated periods. In contrast,

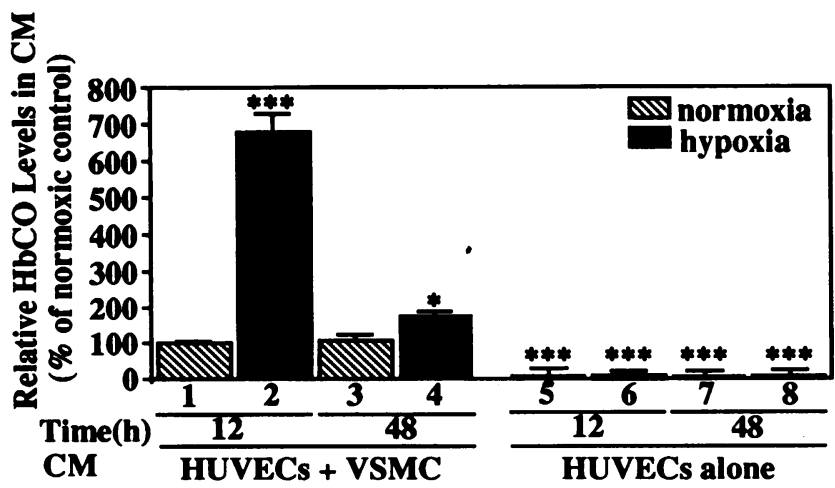

Figure 2. Measurement of $\mathrm{HbCO}$ in conditioned media $(C M)$. Bars $1-$ 4 show levels of $\mathrm{HbCO}$ in media conditioned by HUVECs and VSMC cultured together and exposed to normoxia or hypoxia for 12 (bars 1 and 2 , respectively) or $48 \mathrm{~h}$ (bars 3 and 4 , respectively). Bars 5-8 show levels of $\mathrm{HbCO}$ in media conditioned by HUVECs alone exposed to normoxia or hypoxia for 12 (bars 5 and 6 ) or $48 \mathrm{~h}$ (bars 7 and 8 ). The values are shown as percentages of $\mathrm{HbCO}$ levels in media conditioned by HUVECs and VSMC exposed to normoxia for $12 \mathrm{~h}$. ${ }^{*} P$ $<0.05, * * * P<0.001$ versus control $($ bar 1$)(n=4)$.
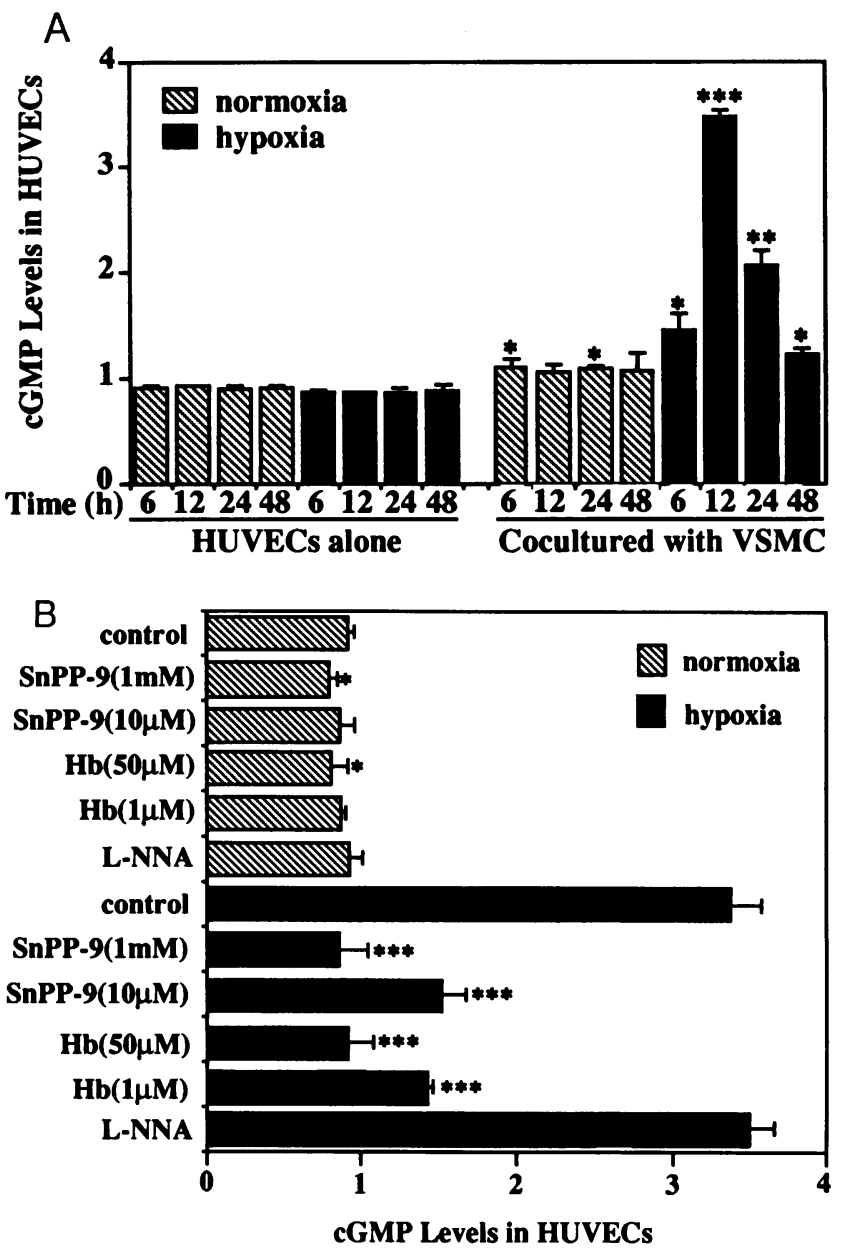

Figure 3. (A) VSMC regulate cGMP levels in adjacent HUVECs under normoxic and hypoxic conditions. cGMP concentrations were determined at the indicated times under normoxia and hypoxia. The data represent cGMP concentrations ( $\mathrm{pmol} / \mathrm{mg}$ cell protein) (mean \pm SEM) on four experiments performed in duplicate. $* P<0.05, * * P<0.01$, $* * * P<0.001$ versus normoxic control in HUVECs alone at each indicated time. $(B)$ VSMC-derived CO increases cGMP production in cocultured HUVECs under hypoxia. cGMP content was determined at $12 \mathrm{~h}$ under normoxia and hypoxia. SnPP-9, Hb, and L-NNA were added at the indicated concentrations. The data represent the cGMP concentrations ( $\mathrm{pmol} / \mathrm{mg}$ cell protein $)($ mean \pm SEM) on four experiments performed in duplicate. $* P<0.05, * * * P<0.001$ versus corresponding control.

cGMP levels in HUVECs cocultured with VSMC were dramatically increased at $12 \mathrm{~h}$ of hypoxia and declined subsequently. The time course of the increase in cGMP levels was essentially similar to the time course of $\mathrm{CO}$ release in the conditioned media. cGMP levels were slightly but significantly elevated in HUVECs cocultured with VSMC under normoxic conditions compared with levels in cells cultured alone. To examine the role of $\mathrm{CO}$ in increasing endothelial cell cGMP levels, we added SnPP-9 (an inhibitor of CO synthesis) to the cultures. As shown in Fig. $3 B$, SnPP-9 lowered cGMP levels in HUVECs in a dosedependent manner under both normoxic and hypoxic conditions. Since metalloporphyrins have been reported to inhibit guanylyl cyclase (13) as well as HO, the suppression of cGMP may be independent of $\mathrm{HO}$ activity. We therefore added $\mathrm{Hb}$, a scavenger of $\mathrm{CO}$ and $\mathrm{NO}$, to the cultures and found that it suppressed 
cGMP dose-dependently. Using L-NNA, we eliminated the role of NO on endothelial cell cGMP production (as also shown by others [14]), demonstrating that it is an HO product, most likely $\mathrm{CO}$, that is the regulator of cGMP under these coculture conditions.

VSMC suppress the hypoxia-induced increases in ET-1 and PDGF-B mRNA in HUVECs. Exogenous administration of CO inhibits the hypoxia-induced increases in the expression of the ET-1, PDGF-B, and vascular endothelial growth factor genes $(15,16)$. We investigated whether $\mathrm{CO}$ at the physiologic concentration released by VSMC could have similar effects on endothelial cell gene expression. First we examined whether the presence of VSMC could regulate ET-1 and PDGF-B gene expression on adjacent endothelial cells. HUVECs cocultured with VSMC were exposed to hypoxia for various periods. The parallel cultures were maintained in the absence of VSMC. Northern blot analysis of HUVEC RNA showed that in the absence of VSMC, ET-1 mRNA levels increased fourfold by $12 \mathrm{~h}$ of hypoxia and sevenfold by $48 \mathrm{~h}$ above control levels (Fig. $4 A$, lanes 3 and 5 , respectively). In contrast, ET-1 mRNA in HUVECs cocultured with VSMC was not induced until 24 h of hypoxia (less than twofold; Fig. $4 \mathrm{~A}$, lane 8 ) and the maximal induction was fivefold above control levels at $48 \mathrm{~h}$ (Fig. $4 A$, lane 9). The middle panel of Fig. $4 A$ shows that the hypoxia-induced increases in PDGF-B mRNA were also suppressed by the presence of VSMC in a pattern similar to those of ET-1 mRNA. In contrast, the levels of $\mathrm{TGF}_{\beta}$ mRNA expression were not altered by VSMC under the same hypoxic conditions (data not shown). These findings suggest that the factor responsible for suppressing hypoxia-induced increases in ET-1 and PDGF-B mRNA is produced from VSMC in the early hypoxic period and its production decreases by $48 \mathrm{~h}$ of hypoxia. Furthermore, its effects are specific for the ET-1 and PDGF-B genes, that is, genes regulated by hypoxia in these cells. A similar pattern of ET-1 expression was observed when VSMC were cocultured with BAECs (Fig. $4 B$ ), indicating that VSMC can alter gene expression in endothelial cells derived from the same or different vascular beds as the smooth muscle cells themselves. Fig. $4 C$ demonstrates graphically the relative changes in mRNA levels of the hET-1, bET-1, and PDGF-B genes in hypoxic endothelial cells incubated alone or in coculture with VSMC for $48 \mathrm{~h}$.

An HO-dependent factor produced by VSMC and inhibited by $H b$ suppresses the hypoxia-induced increases in ET-1 mRNA in HUVECs. VSMC specifically suppressed the expression of hypoxia-responsive genes in endothelial cells with a time course similar to $\mathrm{CO}$ release, indicating that VSMC-derived CO may be the factor responsible for this phenomenon. To examine this, we added $\mathrm{Hb}$, which is a scavenger of $\mathrm{CO}$, or SnPP-9, a potent inhibitor of HO, to the cultures. Furthermore, to eliminate NO as the molecule mediating the suppression of the increases in ET-1 mRNA, we added L-NNA to the cultures, since NO is reported to have the same effect on these genes as CO (15). Fig. 5 A shows Northern blot analysis of RNA from HUVECs exposed to normoxia or hypoxia for $12 \mathrm{~h}$ in the presence or absence of $\mathrm{Hb}, \mathrm{SnPP}-9$, or L-NNA. Under normoxia, neither VSMC nor these reagents had any significant effect on the levels of ET-1 mRNA expression by the endothelial cells (Fig. $5 \mathrm{~A}$, lanes 1-5). In contrast, under hypoxia, SnPP-9 (Fig. $5 A$, lane 8 ) and $\mathrm{Hb}$ (lane 10) reversed the effect of cocultured VSMC on endothelial cells, such that ET-1 mRNA was expressed at high levels, similar to those in HUVECs cultured alone (lane
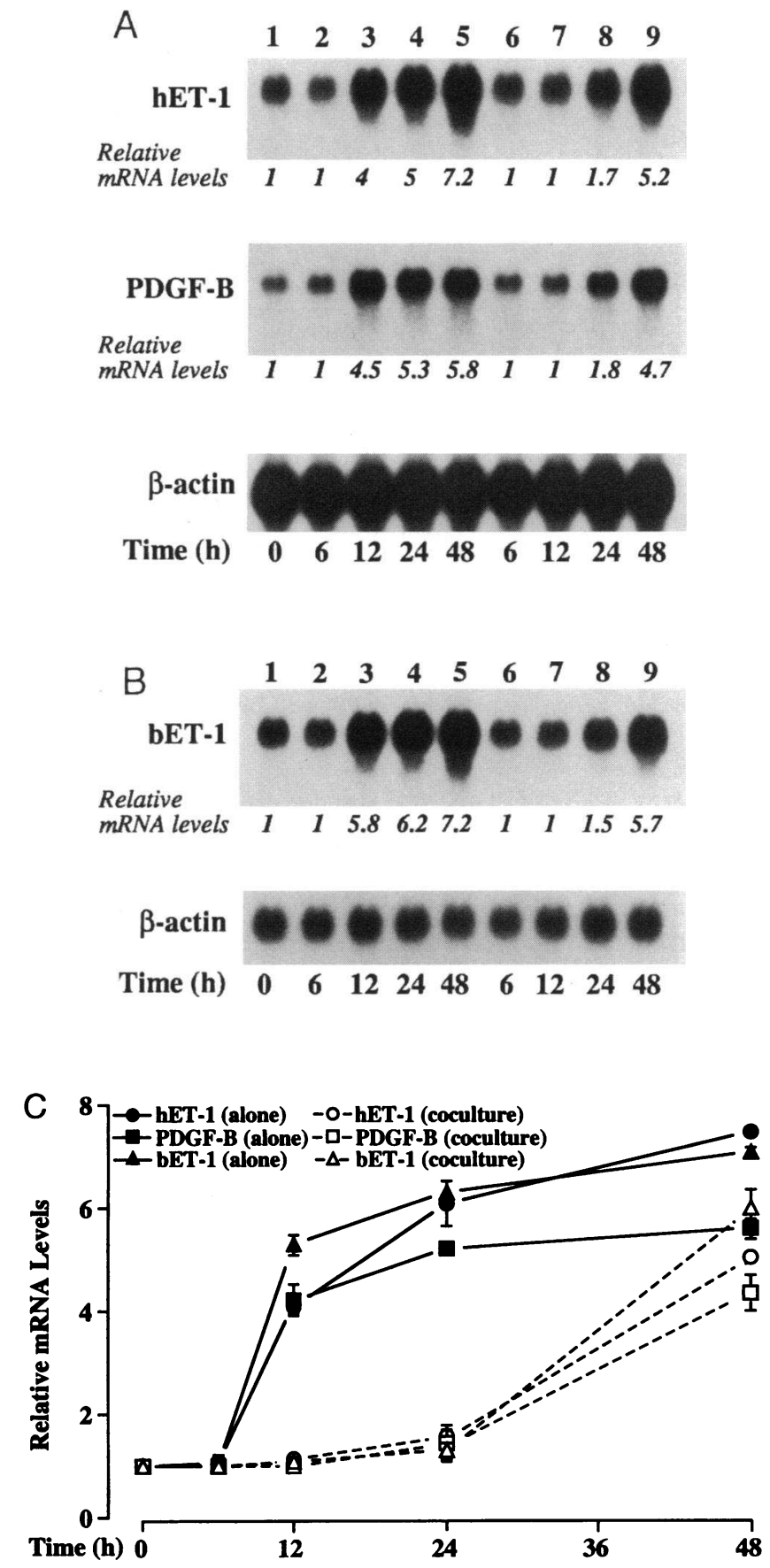

Figure 4. VSMC suppress the hypoxia-induced increases in ET-1 and PDGF-B mRNA. $(A)$ Total RNA was extracted from HUVECs exposed to hypoxia for 6 (lanes 2 and 6 ), 12 (lanes 3 and 7), 24 (lanes 4 and 8 ), and $48 \mathrm{~h}$ (lanes 5 and 9). HUVECs were cultured alone (lanes 1 5) or with VSMC (lanes 6-9), RNA was extracted, and Northern blot analysis was performed. hET-1 mRNA levels and PDGF-B mRNA levels are shown on the upper and middle panels, respectively, and $\beta$-actin on the lower panel. Relative mRNA levels normalized to $\beta$-actin and compared with time 0 control are indicated. $(B)$ RNA was isolated from BAECs cocultured with VSMC. bET-1 transcript levels are normalized to $\beta$-actin as in $A$ and are shown for BAECs cultured alone under hypoxia (lanes $1-5$ ) or in coculture with VSMC (lanes 6-9) for the indicated time period. $(C)$ The effect of coculture on relative mRNA levels of hET-1, bET-1, and PDGF-B (normalized to $\beta$-actin) in endothelial cells exposed to hypoxia for $48 \mathrm{~h}$ is shown graphically. Mean values are indicated \pm SEM from a sum of at least two to six independent experiments. 

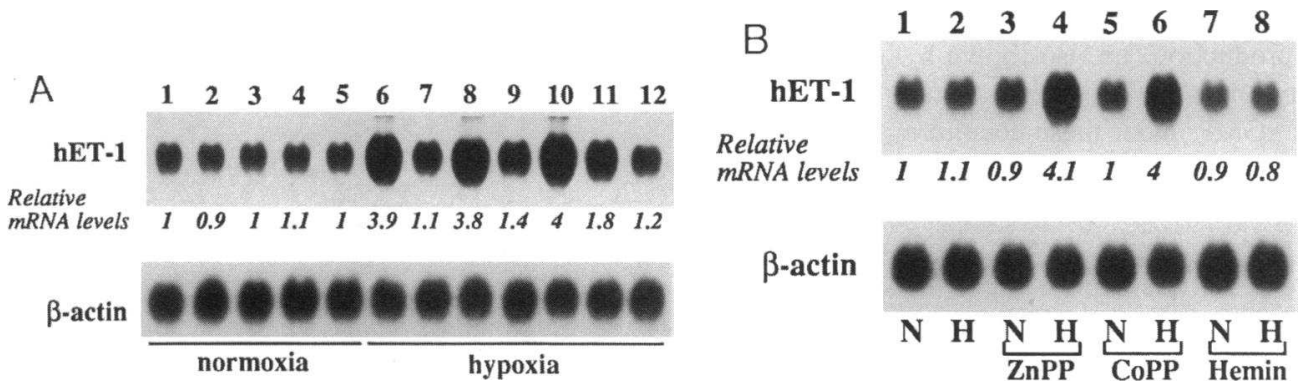

Figure 5. An HO-dependent factor from VSMC inhibited by $\mathrm{Hb}$ is responsible for suppressing hypoxiainduced increases in ET-1 mRNA expression. (A) Total RNA was extracted from HUVECs exposed to normoxia or hypoxia for $12 \mathrm{~h}$, and Northern blot analysis was performed. Lanes $1-5$ show transcripts from HUVECs in normoxia and

6 show ET-1 mRNA from HUVECs cultured alone. Lanes 2 and 7 show ET-1 mRNA levels in HUVECs cocultured with VSMC. Lanes 3 and 8 show HUVECs cocultured with VSMC in the presence of SnPP-9 $(1 \mathrm{mM})$. Lane 9 shows levels of ET-1 mRNA in the presence of lower concentrations of SnPP-9 $(10 \mu \mathrm{M})$ under hypoxic conditions. Lanes 4 and 10 show ET-1 mRNA in HUVECs cocultured with VSMC in the presence of $\mathrm{Hb}(50 \mu \mathrm{M})$ and lane 11 shows $\mathrm{Hb}$ at $1 \mu \mathrm{M}$. Lanes 5 and 12 show levels of RNA in HUVECs cocultured with VSMC in the presence of LNNA $(2.5 \mathrm{mM}$ ). The lower panel shows the blot rehybridized to the $\beta$-actin probe. Relative ET-1 mRNA levels (normalized to $\beta$-actin mRNA) are presented. These data are representative of three independent experiments where the mean fold induction of hET-1 was $4.05 \pm 0.12$ in cells cultured alone under hypoxia, compared with $1.07 \pm 0.1$ under normoxia. In the presence of the various agents, the relative mRNA levels shown approximate the mean values of three experiments \pm 0.12 . $(B)$ Northern analysis was performed on RNA isolated from HUVECs under normoxia $(N)$ or hypoxia $(H)$ in the presence or absence of $\operatorname{ZnPP}(10 \mu \mathrm{M})$, CoPP $(100 \mu \mathrm{M})$, and hemin $(5 \mu \mathrm{M})$ as indicated. Relative mRNA levels of hET- 1 are indicated normalized to $\beta$-actin and are representative of three independent experiments. The mean fold induction of ET- 1 by the metalloporphyrins under hypoxia was $4.07 \pm 0.03$ and the mean basal expression without these agents was $1.1 \pm 0.07$ and $0.93 \pm 0.06$ in the absence or presence of hemin, respectively. ZnPP and CoPP indicate ZnPP-9 and CoPP-9, respectively.

6). L-NNA (Fig. $5 \mathrm{~A}$, lane 12 ), at a dose shown previously to block NO synthesis (15), had no effect on ET-1 mRNA levels in this coculture system. We tested additional inhibitors of $\mathrm{HO}$ and found that, as was the case with SnPP-9, ZnPP-9 and CoPP9 reversed the effects of coculture on ET-1 mRNA levels, allowing for higher expression under hypoxia as in cells cultured alone (Fig. $5 \mathrm{~B}$ ). Hemin, however, an inducer of HO, suppressed ET-1 mRNA levels in cocultured endothelial cells. Taken together, these findings suggest that $\mathrm{CO}$, the product of $\mathrm{HO}$, released by hypoxic VSMC into the conditioned media is responsible for the suppression of hypoxia-induced increases in ET-1 mRNA expression.

VSMC inhibit the hypoxia-mediated increases in ET-1 secretion. To determine whether ET-1 protein accompanies changes in ET-1 gene expression, we measured ET-1 peptide levels in the conditioned media. HUVECs exposed to hypoxia secreted twofold greater ET-1 protein than those in normoxia by $12 \mathrm{~h}$ and fourfold by $24 \mathrm{~h}$ (Fig. $6 \mathrm{~A}$, solid lines). In contrast, ET-1 peptide levels in conditioned media of HUVECs cocultured with VSMC were low, comparable with normoxic control levels at both 12 and $24 \mathrm{~h}$ of hypoxia (Fig. $6 \mathrm{~A}$, dotted lines). By $48 \mathrm{~h}$ of hypoxia, ET-1 levels in the media of HUVECs cocultured with VSMC increased to threefold above normoxic control levels, but were still less than the levels in the media of hypoxic HUVECs cultured alone. These changes in the kinetics of ET-1 protein production by endothelial cells paralleled those in ET-1 mRNA expression under coculture conditions. To examine whether $\mathrm{CO}$ may be responsible for the decreased production of ET-1, we added SnPP-9 or Hb to the cultures. L-NNA was added to examine the effect of NO. Fig. $6 B$ shows the resulting ET-1 peptide levels in the media of cells cocultured for $12 \mathrm{~h}$ under normoxic and hypoxic conditions, in the presence or absence of these agents. Under normoxia, ET-1 peptide levels were not altered with these reagents in coculture. Under hypoxia, ET-1 levels were elevated twofold in HUVECs cocultured with VSMC but only in the presence of $\mathrm{Hb}$ and SnPP-9. These effects of $\mathrm{Hb}$ and SnPP-9 on ET-1 peptide are essentially similar to those on ET-1 gene expression and suggest that $\mathrm{CO}$, the product of HO, decreases the production of ET-1 from endothe- lial cells. Due to the low amounts of PDGF-BB relative to the other PDGF dimers released in the medium of HUVEC (17), PDGF-BB activity was detected in coculture by neutralizing antibody studies described below.

A product of $\mathrm{HO}$ alters VSMC replication predominantly through the regulation of ET-1 and PDGF-BB production. The above data indicate that VSMC exposed to hypoxia for $12 \mathrm{~h}$ release about fivefold greater amounts of $\mathrm{CO}$ into their medium than cells exposed to hypoxia for $48 \mathrm{~h}$ and suggest that $\mathrm{CO}$, the product of $\mathrm{HO}$, may be the factor responsible for suppressing the production of ET-1 and PDGF-B in endothelial cells. PDGF$\mathrm{A}$ is not affected by hypoxia or $\mathrm{CO}(6)$. Both ET-1 and PDGF$\mathrm{BB}$ proteins are known to have a potent proliferative effect on SMC $(18,19)$. We thus inhibited the formation of CO with SnPP-9 and examined VSMC proliferation in the presence of endothelial cells. As shown in Fig. 7, coculture with HUVECs under normoxic or hypoxic conditions increased the number of VSMC slightly to 1.4- and 1.3-fold, respectively, above control levels at $24 \mathrm{~h}$. SnPP-9, the inhibitor of HO, had no additional effect on VSMC number under normoxia (Fig. 7, compare bars 3 and 1), however, replication of VSMC was stimulated almost threefold with SnPP-9 in hypoxia. To confirm that the stimulation in the presence of SnPP-9 was mediated by ET-1 or PDGF$\mathrm{BB}$ released from endothelial cells, polyclonal antibodies to ET1 and PDGF were added to the cultures. Anti-PDGF and antiET-1 together (Fig. 7, bar 5) reduced the VSMC proliferative response markedly to levels of VSMC cultured in the absence of this HO-inhibitor (bar 2). Either antibody alone had only a partial effect on inhibiting VSMC growth in coculture and neither affected the replication rate of VSMC cultured alone (data not shown). These findings suggest that a diffusible factor, generated from hypoxic VSMC and readily inhibited by SnPP9, reduced the proliferation of VSMC by suppressing ET-1 and PDGF-BB production in cocultured endothelial cells.

\section{Discussion}

The mechanisms of hypoxic vasoconstriction in vivo are not well understood. Vasoactive substances, mostly endothelial-de- 

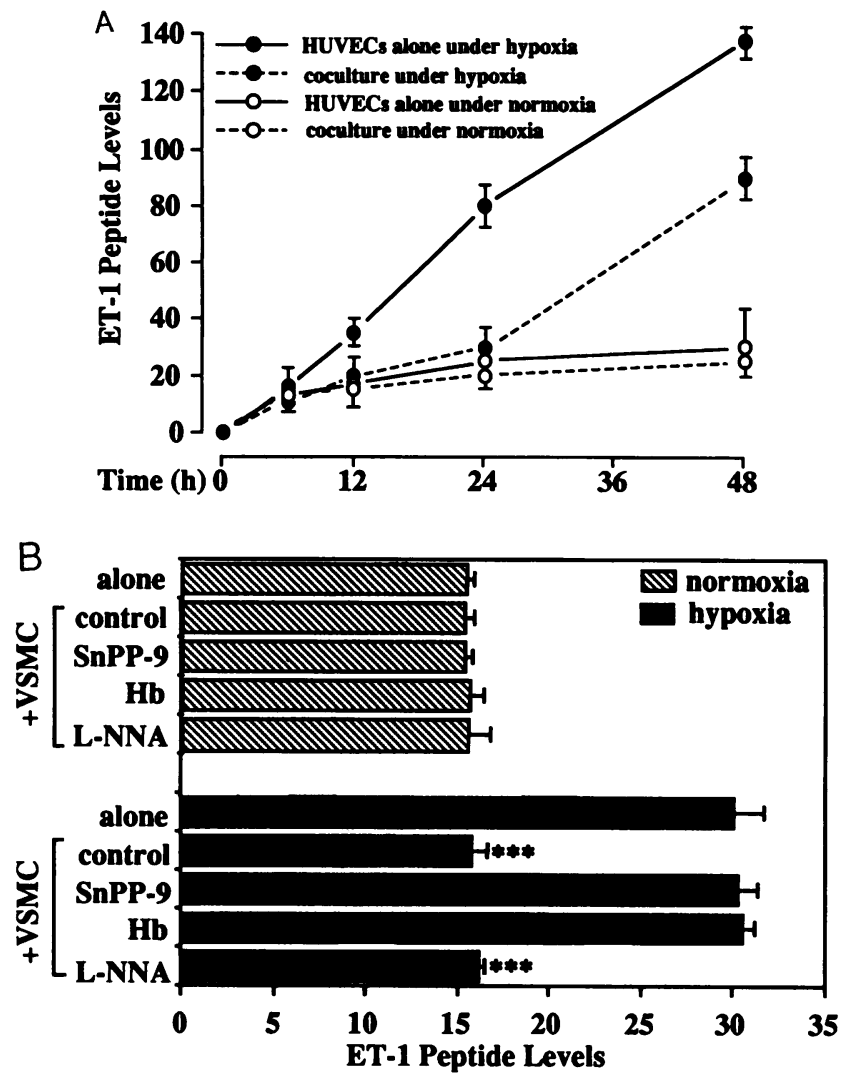

Figure 6. (A) VSMC lower hypoxia-induced increases in ET-1 peptide levels. The media conditioned by HUVECs alone or HUVECs together with VSMC were collected at the indicated times. Determination of ET1 peptide levels was performed. The values are shown as $\mathrm{pM} / 10^{5}$ cell $(n=4)($ mean \pm SEM $)$. Closed circles represent hypoxic exposure and open circles represent normoxic exposure. Dotted lines indicate coculture and solid lines indicate HUVECs cultured alone. $(B)$ VSMC-derived CO lowers ET-1 production by HUVECs. ET-1 peptide levels were determined in conditioned medium from HUVECs in coculture with VSMC after $12 \mathrm{~h}$ of normoxic or hypoxic conditions, in the presence or absence of $\mathrm{Hb}$, SnPP-9, and L-NNA as indicated. The values are shown as $\mathrm{pM} / 10^{5}$ cell $(n=4)($ mean \pm SEM $) * * * P<0.001$ versus VSMC cultured alone.

rived, have been thought to modulate the effects of hypoxia on vascular tone. Hypoxia alters the expression of many mammalian genes. It increases ET-1, PDGF-B, and $\mathrm{IL}_{1}$ expression (6, $7,20)$ and decreases NO production in endothelial cells $(21)$. The perturbation of these vasoconstrictors and vasodilators affects endothelial-smooth muscle cell interactions, leading to hypoxia-related vascular disorders, including excess proliferation and constriction of smooth muscle cells, as well as increased permeability and coagulant function of endothelial cells (5). Although the VSMC layer can contract in response to hypoxia in the absence of the endothelium (22), little is known about VSMC-derived vasoactive substances and their role in modulating vessel tone. We have reported previously that VSMC produce large amounts of $\mathrm{CO}$ under hypoxic conditions, resulting in elevated intracellular cGMP levels (3). VSMC may thus serve to regulate local tone by releasing molecules such as $\mathrm{CO}$ that modulate the action of the endothelial-derived vasomediators on the smooth muscle cells.

Using a coculture system of endothelial cells and VSMC,

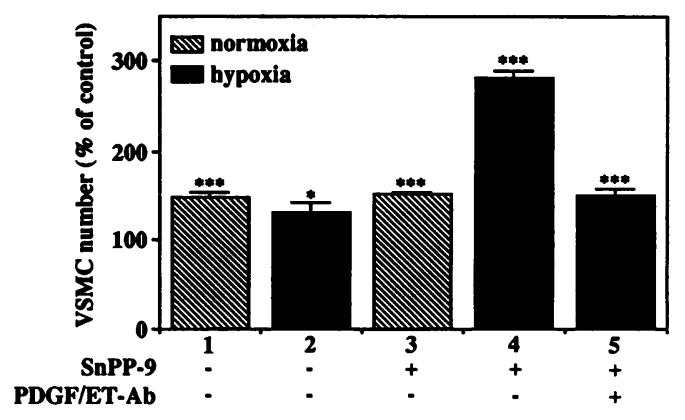

Figure 7. A product of HO controls replication of VSMC through the regulation of ET-1 and PDGF-BB levels in HUVECs. VSMC proliferation rate is determined in coculture with endothelial cells under normoxia or hypoxia in the presence or absence of SnPP-9, PDGF, and ET-1 antibodies $(A b)$ as indicated. The assay was performed after changing media to DME plus 1\% FBS and exposing cells to coculture under normoxia or hypoxia for $24 \mathrm{~h}$. The values are shown as percentages of number of control VSMC in the absence of HUVECs at the start of coculture $(n=6)($ mean \pm SEM $) * P<0.05, * * * P<0.001$ versus control.

we report here that VSMC-derived CO may regulate VSMC proliferation indirectly, by suppressing the production of the endothelial cell-derived mitogens, ET-1 and PDGF-BB. An earlier report had shown that ET-1 release is inhibited in endothelial cells by coculture with cells of vascular media via an unidentified transferable factor (23). We found that under basal, normoxic conditions, ET-1 and PDGF-B production was unaffected by coculture. However, under hypoxic conditions, a factor released by VSMC suppressed the induction of both genes. Our findings suggest that this factor is $\mathrm{CO}$ generated from VSMC via HO-1, since the effect of this factor was abolished by metalloporphyrins which are potent inhibitors of $\mathrm{HO}$, and by $\mathrm{Hb}$, a scavenger of $\mathrm{CO}$, in a dose-dependent manner. In addition, we showed that VSMC-derived $\mathrm{CO}$ may control VSMC growth by suppressing ET-1 and PDGF-BB production: SnPP-9, the inhibitor of CO synthesis, stimulated the proliferation of VSMC, whereas antibodies to PDGF and ET-1 reduced VSMC growth in the presence of SnPP-9. This is the first report to show that endogenous $\mathrm{CO}$ generated by VSMC may regulate endothelial function, which, in turn, affects VSMC growth via feedback mechanisms.

This VSMC-derived factor inhibited by $\mathrm{Hb}$, but unaffected by L-NNA, also increased cGMP levels in cocultured endothelial cells under basal conditions and more dramatically under stimulated conditions of hypoxia. The predominant effect of increased endothelial cell cGMP levels may be the control of endothelial barrier function and platelet adhesion under both basal and hypoxic conditions $(1,24,25)$. Elevated cGMP levels have been reported to inhibit the thrombin-induced increases in ET-1 production (26). However, the effects of VSMC-derived CO on ET-1 and PDGF-B are not mediated by cGMP because neither methylene blue, an inhibitor of guanylyl cyclase, nor 8bromo-cGMP addition to the cultures affects the hypoxic induction of the ET-1 and PDGF-B genes, as we have reported previously (15).

CO shares some of the properties of NO. Both are gas molecules normally produced in the body and capable of binding and activating guanylyl cyclase. Both molecules have been implicated as neuronal messengers in the brain $(27,28)$. NO 
has been reported to affect the production of ET-1 and PDGF$B$ in HUVECs under both basal and stimulated conditions (15). In this study, we showed that CO suppressed ET-1 and PDGF$\mathrm{B}$ gene expression under hypoxic conditions; however, the basal levels of these genes were unaffected by $\mathrm{CO}$. NO has been shown to inhibit cell growth directly by affecting cell cycle events (29). Our findings suggest that VSMC-derived CO may alter VSMC growth indirectly through the regulation of ET-1 and PDGF-B. Further experiments are being conducted to clarify the mechanisms by which $\mathrm{CO}$ may regulate cell growth directly.

We speculate that, in the normal vasculature, the basal production of CO may be lower than NO. Unlike NO, CO is a less potent vasodilator than $\mathrm{NO}(30)$ and may not be the predominant regulator of vessel integrity under basal conditions. However, once the production of NO in endothelial cells is impaired for any reason, such as hypoxia, VSMC-derived CO may take over as the important regulator of gene expression and cGMP levels in vascular endothelial and smooth muscle cells. Additionally, by binding to the heme group of NOS, hypoxia-induced CO may shut down electron flow through the enzyme, leading to further suppression of NOS and NO formation. In this manner, the $\mathrm{CO}$ produced by VSMC may play an important physiologic role in regulating endothelial-smooth muscle cell interactions in response to hypoxia and modulating blood vessel tone.

\section{Acknowledgments}

We thank Drs. Alex Mitsialis, Gary Silverman, and Charles Simmons for their critical review and Kelly Ames for her expert assistance in preparation of this manuscript.

Dr. Kourembanas was supported by grants from the American Heart Association, the William Randolph Hearst Foundation, and by the National Institutes of Health (1P50HL46491).

\section{References}

1. Westendorp, R. G. J., R. Draijer, A. E. Meinders, and V. W. M. van Hinsbergh. 1994. Cyclic-GMP-mediated decrease in permeability of human umbilical and pulmonary artery endothelial cell monolayers. J. Vasc. Res. 31:4251.

2. Lofton, C. E., W. H. Newman, and M. G. Currie. 1990. Atrial natriuretic peptide regulation of endothelial permeability is mediated by cGMP. Biochem Biophys. Res. Commun. 172:793-799.

3. Morita, T., M. A. Perrella, M.-E. Lee, and S. Kourembanas. 1995. Smooth muscle cell-derived carbon monoxide is a regulator of vascular cGMP. Proc. Natl. Acad. Sci. USA. 92:1475-1479.

4. Shreeniwas, R., S. Ogawa, F. Cozzolino, G. Torcia, N. Braunstein, C. Butura, J. Brett, H. B. Lieberman, M. B. Furie, J. Joseph-Silverstein, and D. Stern. 1991. Macrovascular and microvascular endothelium during long-term hypoxia: alterations in cell growth, monolayer permeability, and cell surface coagulant properties. J. Cell. Physiol. 146:8-17.

5. Ogawa, S., H. Gerlach, C. Esposito, A. Pasagian-Macaulay, J. Brett, and D. Stern. 1990. Hypoxia modulates the barrier and coagulant function of cultured bovine endothelium. J. Clin. Invest. 85:1090-1098.

6. Kourembanas, S., R. L. Hannan, and D. V. Faller. 1990. Oxygen tension regulates the expression of the platelet-derived growth factor-B chain gene in human endothelial cells. J. Clin. Invest. 86:670-674.

7. Kourembanas, S., P. A. Marsden, L. P. McQuillan, and D. V. Faller. 1991. Hypoxia induces endothelin gene expression and secretion in cultured human endothelium. J. Clin. Invest. 88:1054-1057.

8. Shweiki, D., A. Itin, D. Soffer, and E. Keshet. 1992. Vascular endothelial growth factor induced by hypoxia may mediate hypoxia-initiated angiogenesis. Nature (Lond.). 359:843-845.

9. Brogi, E., T. Wu, A. Namiki, and J. M. Isner. 1994. Indirect angiogenic cytokines upregulate VEGF and bFGF gene expression in vascular smooth muscle cells, whereas hypoxia upregulates VEGF expression only. Circulation. 90:649652 .

10. Itoh, Y., M. Yanagisawa, S. Ohkubo, C. Kimura, T. Kosaka, A. Inoue, N. Ishida, Y. Mitsui, H. Onda, M. Fujino, and T. Masaki. 1988. Cloning and sequence analysis of cDNA encoding the precursor of a human endotheliumderived vasoconstrictor peptide, endothelin: identity of human and porcine endothelin. FEBS Lett. 231:440-444.

11. Derynck, R., J. A. Jarrett, E. Y. Chen, D. H. Eaton, J. R. Bell, R. K Assoian, A. B. Roberts, M. B. Sporn, and D. V. Goeddel. 1985. Human transforming growth factor- $\beta$ complementary DNA sequence and expression in normal and transformed cells. Nature (Lond.). 316:701-705.

12. Gelmann, E. P., E. Petri, A. Cetta, and F. Wong-Staal. 1982. Deletions of specific regions of the simian sarcoma-associated virus genome are found in defective viruses and in the simian sarcoma virus. J. Virol. 41:593-604.

13. Ignarro, L. J., B. Ballot, and K. S. Wood. 1984. Regulation of soluble guanylate cyclase by porphyrins and metalloporphyrins. J. Biol. Chem. 259:62016207.

14. Yokokawa, K., H. Tahara, M. Kohno, A. K. Mandal, M. Yanagisawa, and T. Takeda. 1993. Heparin regulates endothelin production through endotheliumderived nitric oxide in human endothelial cells. J. Clin. Invest. 92:2080-2085.

15. Kourembanas, S., L. P. McQuillan, G. K. Leung, and D. V. Faller. 1993 Nitric oxide regulates the expression of vasoconstrictors and growth factors by vascular endothelium under both normoxia and hypoxia. J. Clin. Invest. 92:99104.

16. Goldberg, M. A., and T. J. Schneider. 1994. Similarities between the oxygen-sensing mechanisms regulating the expression of vascular endothelial growth factor and erythropoietin. J. Biol. Chem. 269:4355-4359.

17. Bowen-Pope, D. F., C. E. Hart, and R. A. Seifert. 1989. Sera and conditioned media contain different isoforms of platelet-derived growth factor (PDGF) which bind to different classes of PDGF receptor. J. Biol. Chem. 262:1438114384.

18. Hirata, Y., Y. Takagi, Y. Fukuda, and F. Marumo. 1989. Endothelin is a potent mitogen for rat vascular smooth muscle cells. Atherosclerosis. 78:225228.

19. Ross, R., E. W. Raines, and D. F. Bowen-Pope. 1986. The biology of platelet-derived growth factor. Cell. 46:155-169.

20. Shreeniwas, R., S. Koga, M. Karakurum, D. Pinsky, E. Kaiser, J. Brett, B. A. Wolitzky, C. Norton, J. Plocinski, W. Benjamin, et al. 1992. Hypoxiamediated induction of endothelial cell interleukin-1 $\alpha$. J. Clin. Invest. 90:23332339.

21. McQuillan, L. P., G. K. Leung, P. A. Marsden, S. K. Kostyk, and S. Kourembanas. 1994. Hypoxia inhibits expression of eNOS via transcriptional and posttranscriptional mechanisms. Am. J. Physiol. 267:H1921-H1927.

22. Madden, J. A., M. S. Vadula, and V. P. Kurup. 1992. Effects of hypoxia and other vasoactive agents on pulmonary and cerebral artery smooth muscle cells. Am. J. Physiol. 263:L384-L393.

23. Stewart, D. J., D. Langleben, P. Cernacek, and K. Cianflone. 1990. Endothelin release is inhibited by coculture of endothelial cells with cells of vascular media. Am. J. Physiol. 259:H1928-H1932.

24. Kubes, P. 1993. Nitric oxide-induced microvascular permeability alterations: a regulatory role for cGMP. Am. J. Physiol. 265:H1909-H1915.

25. Yamada, Y., T. Furumichi, H. Furui, T. Yokoi, T. Ito, K. Yamauchi, M. Yokota, H. Hayashi, and H. Saito. 1990. Roles of calcium, cyclic nucleotides, and protein kinase $\mathrm{C}$ in regulation of endothelial permeability. Arteriosclerosis. 10:410-420.

26. Boulanger, C., and T. F. Luscher. 1990. Release of endothelin from the porcine aorta. Inhibition by endothelium-derived nitric oxide. J. Clin. Invest. 85:587-590.

27. Snyder, S. H. 1992. Nitric oxide: first in a new class of neurotransmitters Science (Wash. DC). 257:494-496.

28. Verma, A., D. J. Hirsch, C. E. Glatt, G. V. Ronnett, and S. H. Snyder 1993. Carbon monoxide: a putative neural messenger. Science (Wash. DC). 259:381-384.

29. Takagi, K., Y. Isobe, K. Yasukawa, E. Okouchi, and Y. Suketa. 1994. Nitric oxide blocks the cell cycle of mouse macrophage-like cells in the early $\mathrm{G} 2$ + M phase. FEBS Lett. 340:159-162.

30. Furchgott, R. F., and D. Jothianandan. 1991. Endothelium-dependent and independent vasodilation involving cyclic GMP: relaxation induced by nitric oxide, carbon monoxide and light. Blood Vessels. 28:52-61. 